Miscelánea Medieval Murciana. Vol. XVIII. Págs. 23-38

\title{
JORQUERA Y ALCALÁ DEL RÍO JÚCAR A FINES DEL MEDIEVO. DOS VILLAS DEL MARQUESADO DE VILLENA
}

\author{
Alfonso Franco Silva \\ Universidad de Cádiz
}

RESUMEN

Alcalá del Río Júcar y Jorquera, situadas al Noreste de la provincia actual de Albacete, representaban el confín del Marquesado de Villena en su sector septentrional. El estudio se centra en el paso de jurisdicción real a señorial durante los reinados de Juan II, Enrique IV y Reyes Católicos, dentro del amplio contexto del marquesado de Villena. Las fuentes utilizadas son las procedentes del Archivo Ducal de Frías, principalmente.

Alcalá del Río and Jorquera, placed in North-east province of Albacete at present, were the limit of Marquesado of Villena in its northern area. The study is concerning about the step of royal district to manor district during th reigns of John II, Henry IV and th Catholic Kings. The used sources are in the Dukedom of Frias Archive.

PALABRAS CLAVE: señorío, Castilla, fiscalidad, ganadería.

A fines de octubre de 1986 el Instituto de Estudios Albacetenses organizó unas jornadas de trabajo sobre el Marquesado de Villena. En aquellos interesantes y 
apretados días se puso de relieve todo lo que sabíamos, y todo lo que quedaba por saber sobre el marquesado de Villena desde fines del siglo XIII hasta el siglo XVIII, esta curiosa demarcación territorial oscilante siempre entre el realengo y el señorio'. Preocupado desde hace algún tiempo por este tema, ofrezco en este modesto trabajo una serie de noticias sobre las villas de Jorquera y de Alcalá del Júcar procedentes integramente del Archivo Ducal de Frías, y un interesante arancel en el que figuran las cantidades que debían percibir el concejo y los señores de ambas villas por el uso del ganado que entraba en los términos del primer pueblo citado ${ }^{2}$.

\section{JORQUERA. DE ALFONSO PÉREZ DE VIVERO A LOS PACHECO}

Jorquera, Alcalá y en general la zona del Júcar fue ocupada por Alfonso VIII tras la victoria de las Navas de Tolosa ${ }^{3}$. A fines del XIII ambas villas se integran en los dominios de D. Juan, hijo del infante D. Manuel, y por tanto pasan a formar parte a lo largo del siglo siguiente del marquesado de Villena ${ }^{4}$. En 1395 Enrique III incorpora las tierras de ese señorío a la Corona, tras confiscárselas a los herederos de D. Alfonso de Aragón, y promete a los vecinos de Jorquera y Alcalá que nunca volverán a ser enajenadas de la Corona. Así fue, en efecto, hasta los años cuarenta del siglo XV en que Juan II decide un nuevo destino para ambas villas. En 1440 entrega Villena al Dr. Pero Yáñez y las villas del Júcar a otro hombre de su confianza, el Contador Mayor Alonso Pérez de Vivero's. Las causas

I El resultado de esas jornadas tuvo su correspondiente publicación: Congreso de Historia del Señorio de Villena. Albacete, 1987.

2 El arancel en Archivo Ducal de Frias (en adelante A.D.F.), leg. 126, $\mathrm{n}^{\circ} 1$.

3 PRETEL MARÍN, Aurelio: Albacete. Tierra de encrucijada. Madrid, 1983, p. 63, y del mismo autor Conquista y primeros intentos de repoblación del territorio albacetense. Albacete, 1986, p. 82.

4 Pertenecieron al marquesado hasta que éste fue confiscado por Enrique III en 1395 a los sucesores de D. Alfonso de Aragón. El monarca prometió a la villa de Jorquera que jamás la enajenaría de la Corona, PRETEL, Aurelio: «Algunas acciones militares de Albacete y su comarca en las luchas de los infantes de Aragón", Al-Basit, Revista de Estudios Albacetenses, ano VII, $\mathrm{n}^{\circ} 10$, abril 1981, p. 29, y PASTOR ZAPATA, José Luis, «Un ejemplo de «apanage» hispánico: el Señorío de Villena (1250-1445)», Revista del Instituto de Estudios Alicantinos, 31 (1980), pp. 15-40. Ver también MITRE FERNÁNDEZ, Emilio: «Señorío y Frontera (el marquesado de Villena entre 1386 y 1402)», Murgetana, XXX, 1969.

5 La donación de Villena a Pero Yáñez en A.D.F., Catálo Antiguo, leg. $51, n^{\circ} 3$. Ver a este respecto LEÓN TELLO, Pilar: Inventario del Archivo de los Duques de Frías II. Casa de Pacheco. Madrid, 1967, pp. 267 y ss. Por lo que se refiere a Jorquera y Alcalá, Aurelio Pretel piensa que ya en 1444 ambas villas se hallaban en poder de Alonso Pérez de Vivero, la Crónica de Juan II le menciona en 1446 como señor efectivo de los dos concejos. PRETEL, Aurelio: «Algunas acciones militares de Albacete...», Al-Basit, p. 38. Ver también a este respecto mi trabajo: «Alfonso Pérez de Vivero, Contador Mayor de Juan II de Castilla. Un traidor y su fortuna». Hispania. XLVIU/165 (1987), pp. 83-116. 
que explican la donación de estas villas a estos dos personajes las estudia muy detenidamente el profesor Aurelio Pretel en un espléndido trabajo publicado en la Revista de Estudios Albacetences en 19816. Ambas concesiones se inscriben en el marco de una época de tensiones y contiendas entre la Corona y tras ella su mentor el privado Álvaro de Luna, y los infantes de Aragón, que intentaban conquistar el poder en el reino de Castilla, aventura ésta que finalizará en 1445 con la derrota de los infantes en la batalla de Olmedo. Pero antes de llegar a este desenlace, y a comienzos de 1440, las tierras del marquesado de Villena fueron el escenario principal en el que se va a desarrollar una de las fases de esta cruenta batalla por el poder. De esta manera, según Aurelio Pretel, al entregar Villena a Pero Yáñez, Juan II y D. Álvaro de Luna pensaban interponer un enclave controlado por un hombre fiel a la Corona entre las fuerzas enemigas de Juan de Navarra, que ocupaban una parte de las tierras que habían pertenecido al antiguo marquesado de Villena, y los auxilios que podía recibir este último del reino de Valencia?. A pesar de todos estos peligros, el doctor Pero Yáñez pudo afianzarse en Villena, y con muchas dificultades logró consolidar su dominio en esta villa hasta su muerte en $1444^{8}$.

La donación de Jorquera, Alcalá y Ves a Vivero responde a causas similares. Pretel piensa que el Contador Mayor consiguió la jurisdicción sobre estas villas durante la lucha contra los infantes de Aragón, y cree que ya en 1441 habían caído en su poder'. Alonso Pérez de Vivero y el Dr. Pero Yáñez formaban parte de una generación de funcionarios - no hay que olvidar a Rivadeneira y a Fernán López de Saldaña - que jugaron un destacado papel político en la corte de Castilla durante el reinado de Juan II $^{10}$. Algunos habían sido colocados en la administración por Álvaro de Luna, «hombres oscuros» y «personajes menudos» que supieron aprovechar sus carreras y su constante presencia junto al monarca para acceder a la pequeña nobleza. Este es el caso de Alonso Pérez de Vivero y del doctor Pero Yáñez, personajes que han merecido mi atención en dos trabajos recientes".

Con toda seguridad la donación de Villena y la de Jorquera y Alcalá del Río a esos dos funcionarios se hizo de forma provisional a la espera de acontecimientos

$6 \quad$ El trabajo de Aurelio Pretel lo cito en las dos notas anteriores.

7 PRETEL, Aurelio: «Algunas acciones...», p. 33.

8 Ver a este respecto: FRANCO SILVA, Alfonso y MORENO OLLERO, Antonio: «Las primeras ordenanzas municipales de Villena (1440-1445)». Anales de la Universidad de Alicante. 8 (1990-1991), pp. 117-121.

9 PRETEL, Aurelio: «Algunas acciones...», pp. 38 y 43.

10 SUÁREZ FERNÁNDEZ, Luis: Nobleza y Monarquía, Valladolid, pp. 109-111.

11 «Alfonso Pérez de Vivero, Contador Mayor de Juan II de Castilla. Un traidor y su fortuna", pp. 83-116, y en colaboración con A. Moreno Ollero el también ya citado de «L as primeras ordenanzas municipales de Villena (1440-1445)m. Anales de la Universidad de Alicante. Historia Medieval. 8 (1990-1991), pp. 115-145. 
que pusieran fin definitivo a las pretensiones de los infantes. Se trataba de evitar que cayesen en poder del rey de Navarra. Fue, por tanto, una consecuencia de una coyuntura delicada, aunque también influyese en el monarca y en D. Álvaro el deseo de premiar la lealtad y colaboración de ambos servidores. Sin embargo, la Corona disponía en este caso de villas y tierras que formaban parte del marquesado de Villena, señorío que en 1439 en la concordia de Castronuño se acordó entregar al príncipe de Asturias, que lo recibiría en concepto de dote por su matrimonio con la infanta doña Blanca, hija de Juan de Navarra ${ }^{12}$. El pacto firmado en Toledo no se cumplió, y Villena, Alcalá del Río, Jorquera y otras villas continuaron en poder de Juan II. El monarca pudo, por tanto, hacer uso de esas villas para resolver de la mejor manera posible una situación grave. Por consiguiente la solución debía ser provisional, porque cuando cesasen las dificultades las villas así donadas serían de nuevo reclamadas por su legítimo señor, que no era otro que el príncipe de Asturias y su esposa Blanca de Navarra. Lo prueba el hecho de que tanto Pero Yáñez como Vivero encontraron múltiples dificultades y una fuerte oposición a la hora de afianzarse en su nueva posesión ${ }^{13}$. Los partidarios que el rey de Navarra tenía en esas villas eran aún numerosos e importantes y esperaban la ocasión propicia para que retornasen de nuevo a su antiguo amo. El combate de Olmedo provocó un cambio total de la situación.

Un año antes de producirse la derrota de los infantes de Aragón, el futuro Enrique IV hizo saber que no estaba dispuesto a tolerar la enajenación que de Villena había hecho su padre a Pero Yáñez. Nada ocurrió, sin embargo, hasta la desaparición del fiel funcionario. En efecto, la concesión de Villena a Pero Yáñez vulneraba lo acordado en el pacto de Toledo de 1436, y aunque el propio Juan II y su hijo el príncipe de Asturias garantizaran al doctor que no le sería arrebatada la villa sin la debida compensación -la promesa de entrega de la villa extremeña de Granadilla - pronto se vio que las circunstancias políticas del reino hacían imposible el cumplimiento de tal promesa. Todavía unos días antes de morir, Pero Yáñez arrancó al príncipe Enrique la garantía de que no le sería arrebatada Villena ni a él ni a sus herederos sin una enmienda ${ }^{14}$. Sin embargo, la muerte de Pero Yáñez precipitó los acontecimientos y fue aprovechada por Juan Pacheco, privado del futuro Enrique IV, que desde hacía algún tiempo se hallaba interesado en conseguir para su linaje las tierras que habían formado parte del antiguo marquesado, y entre ellas la villa de Villena. Pacheco quería apoderarse de Villena

12 FRANCO SILVA, Alfonso y MORENO OLLERO, Antonio: «Las primeras ordenanzas municipales...", p. 116.

13 Ibidem, pp. 116-121.

14 SOLER GARCíA, José María: «La donación de Villena al Dr. Periáñez en 1440», en Studia Historica in honorem Vicente Martín Morella. Alicante, 1985, p. 438. El documento en cuestión se halla en A.D.F., Catálogo Antiguo, leg. 51, n 3. 
mucho antes de morir Pero Yáñez, y así lo había manifestado ante el príncipe de Asturias y ante el omnipotente Condestable D. Álvaro de Luna. Para conseguir sus propósitos Juan Pacheco llegó a un acuerdo en enero de 1444 con el condestable Luna, pacto este que escondía una verdadera confederación contra los infantes de Aragón; ambos personajes se declaraban en las cláusulas de este documento que serían amigos de sus amigos y enemigos de sus enemigos ${ }^{15}$. El acuerdo y los problemas posteriores han sido estudiados por mí en un trabajo reciente ${ }^{16}$. El condestable prometía a Pacheco en el mes de enero de 1444 que lograría obtener del rey la promesa de darle Villena. Dos meses más tarde, el 3 de marzo de ese año, Juan II, aconsejado por su privado Álvaro de Luna que, para acabar con sus enemigos los infantes de Aragón necesitaba del concurso y la amistad del príncipe de Asturias, y por tanto de la de Pacheco, concecedía a este último Villena con su fortaleza, jurisdicción y rentas. y le prometía que se la entregaría dentro de los sesenta días posteriores a la fecha de esa carta ${ }^{17}$. En este albalá el monarca pasaba por alto los derechos que a Villena podrían tener tanto su hombre de confianza Pero Yáñez, que en ese momento poseía la villa, como los herederos de éste último. Ante la insistencia de Juan Pacheco por apoderarse de Villena, el monarca y don Alvaro no tuvieron mas remedio que ceder. Por eso el doctor Pero Yáñez temía que le arrebatasen la villa a pesar de las promesas que a este respecto le habían hecho Juan Il y el príncipe Enrique. El viejo doctor antes de morir sabía que perdería Villena aunque hizo todos los esfuerzos posibles para evitarlo. El propio Juan II intentó a la desesperada que Pacheco en lugar de recibir Villena se contentase con 700 vasallos en tierras de Sevilla o Córdoba. Nada, sin embargo, pudo hacerse ante la voracidad del privado del heredero. El 21 de noviembre de 1444, el príncipe de Asturias, en un albalá fechado en Murcia, aprovechaba la desaparición de Pero Yáñez para reclamar la villa de Villena «por ser lugar del marquesado de Villena e me pertenesçe por razón de la dote que me fue prometida al tienpo que se concertó mi casamiento con la princesa mi muy cara e amada mugen ${ }^{18}$. Cuando otorga ese albalá, el futuro Enrique IV y su mayordomo mayor Juan Pacheco habían ocupado por la fuerza, tras un duro asedio, la villa y fortaleza de Villena. Los herederos del doctor Pero Yáñez nada pudieron hacer frente al poder del príncipe Enrique. En ese mismo día en que el heredero de Castilla hace saber a su padre que ha tomado Villena para sí, el privado de Juan II, Álvaro de Luna, y Juan Pacheco se comprometían a lograr del monarca una compensación para Juan de Ulloa por la pérdida de su villa ${ }^{19}$. El príncipe Enrique y Pacheco no

15 La confederación firmada en Talavera se encuentra en A.D.F., Catálogo Antiguo, leg. 56.

16 Ver nota $\mathrm{n}^{\circ} 12$.

17 A.D.F. Catálogo Antiguo, leg. 51. El albalá va firmado por el monarca en Tordesillas.

18 A.D.F. Catálogo Antiguo, leg. 51, $n^{\circ} 3$.

19 Ibidem. 
habían tomado Villena pacíficamente, sino por la fuerza, despojando a los Ulloa de la posesión de su villa. La usurpación estaba ya hecha. Los Ulloa no se atrevieron a denunciarla. El príncipe Enrique había conquistado Villena para donársela a su favorito. La batalla de Olmedo fue el pretexto y la ocasión idónea para conceder Villena a Pacheco. Juan II y D. Álvaro de Luna, con el concurso del príncipe de Asturias y de su privado Pacheco, lograron derrotar a los aragoneses. El precio impuesto por Pacheco fue no sólo la donación de Villena, sino también de otras villas como Sax y Yecla y, lo que era mucho más importante, la concesión del título ambicionado de marqués de Villena. En efecto, en las capitulaciones firmadas el 2 de septiembre de 1445 entre Juan II y Álvaro de Luna de una parte, y el príncipe Enrique y Juan Pacheco de la otra, se acordó entre otras cosas que se daría a este último una buena compensación si renunciaba a la villa de Agreda, que pocos meses antes le había concedido el rey ${ }^{20}$. Unos días más tarde, el 13 de septiembre, Juan II fija esta compensación en 1.000 vasallos que le serían entregados a Pacheco en la villa de Villena y su tierra, en las de Sax y Yecla y en varias aldeas de la tierra de Alarcón, que serían oportunamente separadas de la jurisdicción de esa última villa ${ }^{21}$. Pacheco había conseguido su objetivo, más aún cuando el monarca le había concedido el día anterior el título de marqués de Villena ${ }^{22}$. Pocos días después, un privilegio del príncipe de Asturias otorgado en Almagro, confirmaba a su privado en la donación que su padre le había hecho de Villena, Sax, Yecla y las aldeas de Alarcón ${ }^{23}$. El heredero del trono castellano comisionaba al bachiller Mateo Fernández de Medina del Campo para que fuese a esas villas y contase el número de vecinos que vivian en ellas. El bachiller cumplió escrupulosamente su cometido y asi contó 420 vasallos en las villas de Villena, Sax y Yecla, y los restantes 580 se escogieron en la tierra de Alarcón ${ }^{24}$. Por último, Juan II confirmó las posesiones de Pacheco en un solemne privilegio rodado dado en Toro el 6 de abril de $1446^{25}$. De esta manera Villena se incorporaba a los dominios de Juan Pacheco. En definitiva, la donación de Villena a Pero Yáñez, como afirma D. José María Soler, «se había hecho en tiempo de necesidad y con el propósito de revocarla en cuanto el tiempo amainase», pero, al dar la villa al doctor, el monarca vulneró las normas del «apanage» regio, transgresión esta que sería bien aprovechada por Juan Pacheco para anexionarse no sólo esa villa, sino también muy poco después el marquesado entero, más extenso y poderoso que nunca ${ }^{26}$.

20 A.D.F. Catálogo Antiguo, leg. 56.

21 A.D.F. Catálogo Antiguo, leg. $3, n^{\circ} 18$.

22 A.D.F. Catálogo Antiguo, leg. 31, no 5.

23 A.D.F. Catálogo Antiguo, leg. 3, números 21 y 24.

24 A.D.F. Catálogo Antiguo, leg. 3, $n^{\circ} 25$.

25 A.D.F. Catálogo Antiguo, leg. $4, n^{\circ} 4$.

26 SOLER, José María, art. cit., p. 442. 
Si me he detenido en el análisis del caso de Villena y su posterior incorporación a los dominios de Juan Pacheco es porque en las villas de Jorquera y Alcalá sucede lo mismo. Pérez de Vivero había conseguido ser señor de Jorquera, Alcalá del Júcar y Ves, aprovechando las dificultades de la monarquía en su lucha contra los infantes de Aragón. Pasado este peligro, tras el episodio de Olmedo, no habrá ya razón alguna para que el Contador Mayor siguiese reteniendo las tres villas del Júcar. Juan Pacheco, que tras recibir Villena y la concesión del título de marqués en 1445, trataba de reconstruir en su provecho todo el antiguo señorío de los Manuel, necesitaba las villas del Júcar, porque, como afirma el profesor Pretel, esas villas dividían casi en dos las posesiones adquiridas recientemente ${ }^{27}$. Por ello, para Pacheco era empresa de la máxima urgencia arrebatarle las mencionadas villas y reintegrarlas a la primitiva unidad del señorío de Villena, al que habían pertenecido en tiempos pasados, por el procedimiento que fuese necesario. En 1451 un acuerdo ventajoso para Vivero pondría en manos de Pacheco las villas citadas, que así se incorporaban a los dominios del linaje ${ }^{28}$.

En medio de las luchas constantes en la zona del Segura y antes de pasar a poder de Juan Pacheco, el concejo de Jorquera procedió a organizar en 1447 la tabla de impuestos que debían pagar los ganaderos que llevaban sus ganados a pastar en sus términos. El documento que ha llegado hasta nosotros, y que publicamos como apéndice al final de este trabajo, es de un gran interés. En él se encuentran enumerados los derechos que cobraba el concejo de Jorquera a los ganaderos forasteros por el uso y disfrute de sus pastos y se especifican quiénes deben pagar según su procedencia. Sin duda alguna este arancel procede de otro más antiguo y mucho más completo que organizó en 1380 el marqués de Villena D. Alfonso de Aragón, y que ha sido publicado por Aurelio y muy bien estudiado por $\mathbf{M}^{2}$ Isabel del Val Valdivieso ${ }^{29}$. Continuó vigente después de la incorporación de Jorquera a los dominios de los Pacheco.

Por desgracia la documentación que de ambas villas se conserva en el Archivo Ducal de Frías resulta particularmente escasa para conocer su historia, al menos para el siglo XV. Sin embargo la información que ha llegado hasta la actualidad no carece de interés al respecto y en ella nos vamos a basar para ofrecer al posible lector algunos temas importantes que permanecían inéditos hasta el momento y que pueden resultar de alguna manera ilustrativos para conocer el carácter y la naturaleza de las relaciones que mantenían dos villas de señorío con respecto al marqués de Villena.

27 PRETEL, Aurelio: «Las tierras albacetenses en la política castellana de mediados del siglo XV (1448-1453)». Anales del Centro de la UNED de Albacete. 5 (1983), p. 351.

28 PRETEL, Aurelio: "Algunas acciones...», Al-Basit, p. 51.

29 El artículo de Aurelio Pretel está publicado en Studia Historica in honorem Vicente Martinez Morellá. Alicante, 9 (1985), y el de $\mathrm{M}^{2}$ Isabel del Val en Congreso de Historia del Señorio de Villena. 
Hasta el año 1364 Alcalá del Júcar era una aldea que pertenecia a la jurisdicción del concejo de Jorquera. En ese año un albalá de Pedro I la convierte en villa autónoma con concejo y términos propios ${ }^{30}$. El monarca, en ese mismo documento, concede la villa a su hijo Sancho, permite a los vecinos que elijan cada año sus propias autoridades municipales por el día de Pascua y obliga a su concejo a que tenga términos de aprovechamiento común con Jorquera y paguen a su hijo los mismos tributos y rentas que habían satisfecho tradicionalmente a los Manuel, sus antiguos señores. Desde ese año, por tanto, comienza a ser Alcalá una villa propia. Tras la guerra de sucesión castellana, en la Concordia de Toledo de 1480, los Reyes Católicos castigaron al marqués de Villena por haber apoyado el bando de Juana la Beltraneja con la pérdida de una buena parte de sus señoríos y únicamente le permitieron que conservase en tierras de Albacete las villas de Alcalá y Jorquera $^{3 !}$. En efecto, dos provisiones otorgadas por los monarcas el 27 de febrero y el 4 de marzo respectivamente de ese año y a petición del marqués, le concedían la jurisdicción sobre Alcalá con sus tributos y las rentas de su puerto seco y también la villa de Jorquera con sus rentas, pechos y derechos, siempre que Villena cumpliese uno de los artículos del acuerdo firmado en Toledo, que obligaba a entregar Chinchilla a la Corona, y después recibiría como compensación Jorquera, que le había sido confiscada por los Reyes Católicos y de la que obtendría confirmación de nueva merced ${ }^{32}$.

Tras la pérdida de una gran parte de sus dominios en Villena y en tierras de Albacete y Murcia, los Pacheco tuvieron que enfrentarse en sus villas del Júcar a problemas que les plantearon algunas de sus antiguas villas, que ahora pertenecían a la Corona. Por de pronto las relaciones entre Iniesta y Jorquera después de 1480 no fueron nada cordiales: robos de ganado, invasión de términos y otros litigios jalonan este conflicto. En 1490 los Reyes Católicos obligan al gobernador del marquesado de Villena a que restituya a los concejos de Jorquera y Alcalá del Río ciertos ganados que los vecinos de Iniesta les habían robado al pasar por el puente de Arrisques ${ }^{33}$. Unos años más tarde, en 1527 , volvieron a surgir rencillas entre esos concejos. El 10 de enero de 1527 una sentencia de la Real Chancillería de Granada obligaba a los vecinos de Iniesta que labrasen en los términos de Jorquera a que pagasen en concepto de terrazgo una fanega de cada doce, y a los que labrasen en los términos de Alarcón 50 fanegas mitad de trigo y la otra mitad de centeno, que deberían quedar para los propios de esas dos villas y además paga-

30 A.D.F., leg. $131, n^{\circ} \mathrm{L}$.

31 Sobre la concordia ver documentos en A.D.F., Caja $7, n^{\circ} 2$, Caja $131, n^{\circ} 2$ y Caja $125, n^{\circ} 1$. Ver a este respecto el trabajo de Juan Torres Fontes: «Lat conquista del marquesado de Villena en el reinado de los Reyes Católicos». Hispania, L (1953).

32 A.D.F. Caja $125, n^{\circ} 1$ y $131, n^{\circ} 2$.

33 A.D.F. Caja $125, n^{\circ} 3$. 
rían otros $30 \mathrm{mrs}$. a los caballeros de sierra para que les dejasen rozar y coger esparto por cada yunta de ganado ${ }^{34}$. Un año más tarde, el 13 de enero de 1528 , el marqués D. Diego López Pacheco llegó a un acuerdo, tras un largo litigio, con el concejo de Iniesta acerca del cobro del servicio y montazgo de los ganados de esta última villa que pastaban en los términos de Jorquera ${ }^{35}$. Se concertó que el marqués percibiría de esos ganados seis cabezas de cada mil, apartándose de la pretensión de percibir otras tres cabezas por derechos de borra, asadura y pontaje.

Al mismo tiempo, en 1484 D. Diego López Pacheco tuvo que hacer frente al pleito que le planteó la Mesta por las excesivas imposiciones que éste llevaba por los derechos del montazgo, borra y asadura de todos los ganados que pasaban por el término de Jorquera ${ }^{36}$. Cinco años más tarde una ejecutoria de los Reyes Católicos, dada en Medina del Campo el 28 de febrero de 1489, daba la razón al marqués de Villena y le amparaba en la percepción de esos derechos recogidos en el arancel de $1447^{37}$. Lo mismo sucedió cuando la villa de Chinchilla pretendió cobrar los mismos derechos que Jorquera ${ }^{38}$.

Semejantes problemas se plantearon también con las villas de Albacete, Tobarra y Yecla que pretendían tener pastos de aprovechamiento común con Jorquera. En efecto, así había sido desde siempre, pero la situación cambió después de que esas tres villas pasaran al realengo. El marqués de Villena adehesó los montes de Jorquera y los tres concejos protestaron a los Reyes Católicos por la violación de privilegios tan antiguos. En 1499 la Audiencia de Ciudad Real dio la razón al marqués: se le permitía que percibiese de los concejos de Albacete, Chinchilla, Tobarra y Yecla los derechos de servicio y montazgo si querían usar esos pastos, además de los que pagaban anteriormente que eran la borra y la asadura y $50 \mathrm{mrs}$. más por cada corte y tala que hiciesen en los montes del término de Jorquera ${ }^{39}$.

Problemas más graves se presentaron con el obispado de Cartagena por la percepción de los diezmos de Jorquera. Tras una serie de enfrentamientos y conflictos se llegó finalmente a un acuerdo el 11 de diciembre de $1535^{40}$. En esta concordia se acordó: 1) que los diezmos de Jorquera y los lugares de su tierra, que son Mahora, San Juan de Villamalea y Cenizate se recogiese en cada uno de ellos; 2) al marqués le correspondería cobrar las tercias de todas esas villas y lugares; 3) que los frutos del diezmo no se juntasen con los que el marqués llevaba en esas villas en concepto de terrazgo; y 4) ya que los lugares de Mahora, Villamalea y

34 A.D.F. Caja $128, \mathrm{n}^{\circ} 8$.

35 Ibidem.

36 A.D.F. Caja 126, $n^{\circ} 3$.

37 A.D.F. Caja $126, n^{\circ} 5$.

38 A.D.F. Caja $124, n^{\circ} 4$.

39 A.D.F. Caja $124, n^{\circ} 1$.

40 A.D.F. Caja 127 y $128, n^{\circ} 1$. 
Cenizate se han vuelto a poblar de nuevo se destinaría el rediezmo de esos frutos, que el marqués y su padre han llevado y siguen llevando y en ello consienten el Cabildo y Obispo de Cartagena, para dotar a las fábricas de las iglesias que se han construido en esos pueblos; de esta manera Villena quedaba obligado a gastar el fruto de ese rediezmo en edificar, reparar y sustentar las iglesias de esos lugares y en comprar sus ornamentos. El acuerdo fue aprobado por el papa Paulo III en una bula expedida en Roma el 11 de octubre de 1536.

A este respecto, conocemos bien la situación de las iglesias de esos lugares por un precioso informe posterior que nos describe que todas ellas fueron construidas en la primera mitad del $\mathrm{XVI}^{41}$. Por lo que respecta a la iglesia del lugar de Mahora, el marqués de Villena se ha gastado en su edificacion la cantidad de $794.012 \mathrm{mrs}$. El edificio es de una sola nave, tiene bóveda de piedra y una capilla en la cabecera donde se halla el coro, tres retablos y uno muy bueno en el altar mayor. La iglesia está prácticamente construida, a falta tan sólo de la bóveda y de la cubierta del tejado, cuyas obras se estima que costarán unos 500 o 600 ducados. La iglesia de Villamalea está también terminada, pero es muy pequeña para el número de personas que habitan en el pueblo y en ella se ha hecho una torre, harto superflua para un lugar como éste, que ha costado 4.000 ducados y a la que sólo le falta el piso de arriba. Como la torre se encuentra a los pies de la iglesia, es forzoso que ésta se alargue por la cabecera, por lo que se verán obligados a derribar la casa de la tercia que el marqués de Villena posee en ese lugar. La iglesia en cuestión no tiene retablo, sólo sagrario, y por ello será preciso gastarse en ella unos 2.500 ducados o más. Ha recibido esta iglesia del marqués desde el día que comenzó a edificarse unos $311.102 \mathrm{mrs}$. Por otra parte, la iglesia del lugar de Cenizate tiene construido su cuerpo central y es suficiente para la población que la habita, que por cierto va en aumento. No tiene ningún retablo, ni campanario, ni torrecampanario de maderos, y para acabar su construcción le falta además la tribuna y el retablo, y para ello será necesario disponer de una cantidad aproximada de unos 400 ducados. El marqués se ha gastado en ella unos 278.207 mrs. Finalmente, por lo que respecta al lugar de las Navas, se trata de una aldea que ha comenzado a poblarse hace pocos años y continúa creciendo paulatinamente porque el pueblo dispone de buenas labores, su iglesia es muy pequeña y han empezado a remodelarla.

La villa de Jorquera y las aldeas de su tierra se encontraban poco pobladas a fines del siglo $\mathrm{XV}$. De aquí la necesidad de atraer nuevos pobladores que pudieran aportar a las arcas señoriales jugosos ingresos. Por ello, y a fin de que la villa y su tierra incrementasen su población, el marqués se vio obligado a conceder generosas franquicias a sus vecinos. Así, el 18 de septiembre de 1513, respondiendo a las

41 Ibidem. 
súplicas del concejo de la villa que le manifestaba su pobreza y su despoblación, el marqués Diego López Pacheco les hizo merced de que las labores que los vecinos de Jorquera tenían en sus dehesas las siguiesen disfrutando a perpetuidad con la condición de que la cuarta parte de lo que estaba labrado en ellas quedase para herbaje y que cuando esta cuarta parte hubiese descansado lo suficiente procediesen a labrarla, dejando otro tanto de las tierras que estuviesen labradas ${ }^{42}$. Aquella persona que infringiese esta medida quedaría obligada a pagar $600 \mathrm{mrs}$. Por otra parte, Villena eximió de esta concesión a todas aquellas personas que no alcanzasen los 140 almudes de tierra. Además les ordenó que todos los vecinos de la villa que disfrutasen de tierras en las dehesas señoriales le enviasen un inventario de las mismas con sus límites y extensión para dar cumplimiento a la donación anterior. Una política tan generosa no se detuvo, sin embargo, en esta concesión, sino que continuó poco después con otras medidas que tendían a conseguir la finalidad mencionada. En efecto, el 26 de ese mismo mes, el marqués de Villena eximió del pago de las alcabalas que le correspondían a todos los vecinos de Jorquera, a cambio de que la villa le donase las dehesas y otros propios ${ }^{43}$. El marqués se reservaba sin embargo el cobro de las alcabalas de la carnicería, del vino forastero, del aceite por menudo y la de todas aquellas personas procedentes de fuera de la villa que viniesen a vender en día que no fuese feria o mercado. El resultado de estas medidas no se hizo esperar. Jorquera contaba con 90 vecinos en 1513; pues bien, unos años más tarde, en 1531, superaba los 140. Este importante incremento poblacional se atribuía por el concejo de la villa a que gozaban de la exención del pago de las alcabalas. Cuatro años mas tarde, el 13 de octubre de 1535, D. Diego II dio orden a su mayordomo de que entregase a los vecinos del lugar de Mahora, que pertenecía a la jurisdicción de Jorquera, 1.500 fanegas de trigo y 700 u 800 de cebada para que con ellas pudiesen sembrar, debido a la escasez que había habido ese año ${ }^{44}$. Sin embargo y a pesar de todas estas medidas, surgieron unos años más tarde algunos conflictos entre este último lugar y el marqués de Villena por problemas de tributos e imposiciones que los vecinos de Mahora no estaban dispuestos a pagar. Los litigios finalizaron en 1567 con una sentencia ejecutoria de la Real Chancillería de Granada ${ }^{45}$. Los jueces ordenaron al marqués que se abstuviese de cobrar cosa alguna del terrazgo a los vecinos de Mahora, de pan y de semilla, y que dicho lugar pudiese gozar libremente de los aprovechamientos de su término. La Chancillería además eximía a los lugareños de Mahora del pago al marqués de $3 \mathrm{mrs}$. por cada cabeza de ganado por razón de los pastos, de la obligatoriedad de entregarle cada vecino dos gallinas al año en

42 A.D.F. Caja 122 y $123, \mathrm{n}^{\circ} 1$.

43 A.D.F. Caja 124, $n^{\circ} 1$.

44 A.D.F. Caja 136, $n^{\circ} 1$.

45 A.D.F. Caja $136, n^{\circ} 2$. 
reconocimiento de señorío y finalmente de que los frutos del diezmo se pagasen en la era, quedando por tanto libres de la costumbre de conducirlos por su cuenta y en sus carros a la tercería del marqués. Por otra parte, los jueces del alto tribunal granadino intentaron también contentar al señor y para ello determinaron que todos los vasallos de Mahora pagasen al marqués alcabala y veintena, ademas de los $10 \mathrm{mrs}$. que cada vecinos debía darle todos los años como reconocimiento de que él era el propietario eminente de todas las tierras que cultivaban, y por último quedaban obligados a restituir todo lo dado para la fábrica de la iglesia y por razón del pozo y pilar de aguas.

Alcalá del Júcar se vio beneficiada también por una política generosa de franquicias algo similar a las que habían recibido los vecinos de Jorquera. En 1513 el marqués de Villena, a fin de que la población de Alcalá no disminuyese les eximió del pago de la obra de un adarve en la puente de Bóveda, y de la obligación de plantar 2.000 olivas y les concedió que pudiesen labrar las tierras de dentro y de fuera de las dehesas $^{46}$. Unos años más tarde, en 1531, D. Diego donó a los vecinos de esa villa 200 fanegas de trigo para el pósito y $2.000 \mathrm{mrs}$. para los abastos ${ }^{47}$.

Finalmente por lo que respecta a las rentas, derechos y posesiones de los marqueses de Villena en las dos villas del Júcar, disponemos de información, si no completa al menos suficiente. Sabemos que en 1530 Jorquera y su tierra aportaba a los Pacheco unas 3.000 fanegas de trigo procedentes de las numerosas dehesas que poseían término ${ }^{48}$. En efecto, el marqués de Villena tenía en Jorquera y su tierra las siguientes dehesas: La Cañada, El Mármol, Torres, Mormate, Campo Alvillo, Golosalbo, Ruy Domínguez, Santiago, Fardales de Amengibre, Casas de Mari Mínguez, Bollinches, Alborea, Sierra Diel, Pajares, Ballunquer, Gomero, Ballunquer Hondonero, Majadales, Arenillas, Ardales, Cayadorro, Cabeza de Sierra Diel y Cenizate ${ }^{49}$. En total 23 dehesas. Una buena parte de estas tierras le habían sido cedidas por el pueblo en 1513 a cambio, como ya hemos visto, de que el marqués les librase del oneroso pago de las alcabalas. En Cenizate, la última de las dehesas citadas, surgió en el siglo XV el lugar que de ella tomó su nombre. En efecto, en 1349 Cenizate era un heredamiento que pertenecía a Fernán Alvarez, un caballero de Alarcón ${ }^{50}$. Su hija y heredera, Teresa Fernández, casada con Alfonso Fernández de Montoya, vecino de Huete, la vendió en ese año a Benito Pérez, merino de la villa de Iniesta, por $2.500 \mathrm{mrs}^{51}$. El comprador solicitó al concejo de Jorquera que le admitiese como vecino por la posesión de la casa y

\footnotetext{
46 A.D.F. Caja $131, n^{\circ} 4$.

47 Ibidem.

48 A.D.F. Caja $125, n^{\circ} 4$.

49 A.D.F. Caja 136 y 124.

50 A.D.F. Caja 139.

51 Ibidem.
} 
heredamiento de Cenizate, y en efecto fue admitido en 1358 con la condición de que pagase anualmente al concejo $80 \mathrm{mrs}$. de a 10 dineros el maravedi «por las fazenderas de ofiçiales del lugar que si alguna otra persona fuere a poblar el dicho lugar pagase los mismos pechos que les tocasen como a los demas vecinos» ${ }^{52}$. A mediados del siglo XV pasó a poder del concejo de Jorquera.

Si de Jorquera conocemos el número de dehesas que poseía el marqués de Villena, en cambio de Alcalá del Júcar sólo sabemos la renta que le proporcionaba esta villa en concepto de ser puerto seco. Las rentas del puerto de Alcalá se arrendaban a partir de 1532. En ese año, D. Diego II arrendó en Escalona el puerto de Alcalá por cuatro años a García de Ávila, vecino de Granada y Recaudador Mayor de los puertos reales del reino de Castilla por la cantidad anual de 310.250 mrs., con la condición de que se cobrasen en ese puerto las mismas cantidades que se percibían en el puerto de Requena ${ }^{53}$. El marqués impone además a García de Ávila otra serie de condiciones: en primer lugar se reservaba el nombramiento de un fiel en el puerto para que vigilase atentamente cómo se despachaban los mercaderes y los derechos que les llevaban, el sueldo de este oficial quedaría a cargo del señor. Villena le exige también que le pague la cantidad estipulada en las ferias de Medina del Campo, en dos pagas anuales, una el 10 de julio y otra el 10 de diciembre, y con la obligación de darle de fianza en cada uno de esos cuatro años la cantidad de 200.000 mrs. García de Ávila, finalmente, se comprometía a hacer francos y exentos de todas las mercancías y cosas que pasasen por el puerto al marqués, su esposa, su hijo, sus contadores Pedro Núñez de Córdoba y Andrés del Castillo y todos sus vasallos. Estas mismas condiciones se repiten en un contrato de arriendo posterior, también por cuatro años, firmado en 1539 con Tomás Comiel, infanzón vecino de Zaragoza, por la cantidad anual de 300.000 $\mathrm{mrs}^{54}$. Unos años más tarde, el 1 de junio de 1559 , el marqués de Villena procede de nuevo al arriendo del puerto seco de Alcalá a Francisco de Nájera, vecino de Granada, Recaudador Mayor de los puertos secos del rey por 300.000 mrs. anuales, idénticas condiciones que el anterior más la entrega de 8 barriles de aceitunas de Sevilla o en su defecto $2.000 \mathrm{mrs}$., y que todas las cuestiones que se susciten en el puerto sean juzgadas por un juez nombrado por Pacheco ${ }^{55}$. El último contrato de arrendamiento que se conserva en el Archivo Ducal de Frías tiene como

52 En 1401 al lugar de Cenizate se le confirmó una dehesa boyal llamada Boalaje por Martín Ruiz, Alcalde Entregador de la Mesta. En 1422 Sancho Fernández Galbarros, Alcalde Entregador de la Mesta, mandó que se cerrara esa dehesa. En 1570 el concejo de Mahora acordó con el marqués el arriendo a perpetuidad de la dehesa de Boalaje a cambio de entregarle cada año 30 ducados. A.D.F. Caja $139, n^{\circ} 6$ y 7 .

53 A.D.F. Caja $131, \mathrm{n}^{\circ} 5$.

54 lbidem.

55 Ibidem. 
protagonista a un mercader genovés. En efecto, en julio de $1580 \mathrm{D}^{2}$ Juana de Toledo, en nombre y como tutora del marqués D. Juan Fernández Pacheco, arrienda el puerto de Alcalá a Gonzalo Patiño, que lo hace a su vez en nombre del genovés Baltasar Cataño, por seis años y la cantidad anual de $410.000 \mathrm{mrs}^{36}$.

\section{APÉNDICE DOCUMENTAL}

\section{7, Jorquera}

Arancel de los derechos que han de pagar los ganaderos que entren sus ganados en los términos de Jorquera.

A.D.F. Leg. 126, $n^{\circ}$ I.

Primeramente es costumbre muy antigua y aranzel muy viejo y antiguo que cada señor de ganado de tierra de Moya y Aragón y tierra de Albarraçin paga diez y nueve reses del primer millar que so quinze reses al millar y más quatro reses que son borra y asadura y gineta y otra que va delante que se llama reynado, y por costunbre pagan a dozientos maravedis de cada res de rescate. $Y$ estas quatro reses de borra y asadura y gineta y reynado pagase avnque no trayga mas de vn hato de çien cabeças los a de pagar y de todas las demas a tres maravedis por cada vna cabeça que ansi salen las quinze reses que quedan repartidas por millar. $Y$ avnque trayga en cantidad de millares de ganado no deve mas de las dichas quatro reses del primer millar y de los otros millares a quinze rese a dozientos maravedis cada cabeça que salen a tres maravedis por cabeça de todas quantas truxiese y metiere y si no llegaren a çien cabeças no deve mas de a tres maravedis por cabeça y no deve otro derecho alguno.

Tierra de Cuenca y de Molina y ducado de Medinaçeli y sus suelos y tierras con la Parrilla y el Canpillo y Alvaladejo y las Valeras y todos los demas que son suelo de Cuenca y de Molina y ducado deven y pagan segun costunbre y aranzel antiguo diez reses del primer millar y las quatro reses de borra y asadura y gineta y reynado y rescatanse ansy mesmo por dozientos maravedis por cada vna res y estas quatro reses de los quatro derechos los deve avnque no meta syno çien cabeças que sanen a dos maravedis por cabeça y mas las quatro reses de los dichos derechos que se pagan en el primer millar y no en mas, que estas quatro reses las deve avnque no sea el hato syno de çien cabeças y sy no llegan a çien cabeças no deven mas de dos maravedis por cada vna y no otros derechos.

Tierra de Huepte y su suelo y tierra de Alarcon y el suyo y toda la Mancha todos segun costunbre $y$ aranzel antiguo pagan a dos maravedis y no pagan reses

56 Ibidem. 
de derechos como las otras tierras de suso, ni borra, ni asadura, ni gineta, ni reynado, syno solamente de cada res pagan los dichos dos maravedis. Pero segun el tiempo fuere y el ganado acudiere esta al alvedrio del juez y mayordomo para podello creçer y no abaxar, esto es segun la tierra estuviere y el alvedrio de los susodichos.

La villa de Yniesta y su juridiçion pagan por conformidad y sentencia seis reses de cada millar sean muchos o sean pocos los millares, y a dozientos maravedis se rescatan las dichas seis reses que salen a: mill cabeças mill y dozientos maravedis, y çien cabeças por çiento y veynte maravedis, y diez cabeças por doze maravedis, y çinco cabeças por seis maravedis. Y este es el vso y costunbre que con los ganados de la dicha villa y su tierra se a tenido y tiene.

El paso de la puente Torres está en costunbre ynmemorial de pagar todos los señores de ganado que pasan de paso a hervajar fuerza de los terminos de Xorquera por la dicha puente Torres o por la puente de Alcala del Rio de cada cabeça vn maravedi y mas dos reses que son borra y asadura y rescatanse estas dos reses por dozientos maravedis cada res y no otros derechos. Y de cada cabeça de ganado mayor de yegua o vaca o muletas a quatro maravedis por cada cabeça.

Y los ganados serranos que pasan por la puente de Alcalá del Río yendo a ervajar a los reynos de Aragon y Valençia pagan por costunbre ynmemorial de cada cabeça vn maravedi y mas borra y asadura, las quales se rescatan a dozientos maravedis como esta dicho en el capitulo de suso del paso de la puente Torres. Y lo mismo pagan los que vienen a hervajar de los reynos de Aragon y de Valençia a Castilla. Pero los ganados churragos que son tierra de Huepte y suelo de Alarcon y Mancha pagan pasando por la dicha puente de Alcala como sy quedasen pastando en el termino de Xorquera.

Yten que todo ganado mayor de vacas y yeguas y otro genero de ganado mayor cavallar y mular y vacuno y semejantes generos que syendo de tierra de Moya y Aragon pagan viniendo a ervajar como dicho es a diez y ocho maravedis de cada cabeça, y de todas las otras partes susodichas pagan por cada cabeça catorze maravedis y no mas. Esto se entiende de las reses çerriles, que de las que syrven el hato no deven ningunos derechos.

Mahora y San Juan de Villamales tienen por capitulaçion y costunbre que pagan del primer millar doze reses y de los otros millares a nueve reses, que sale al primer millar dos mill y quatroçientos maravedis y de los otros millares a mill y ochoçientos maravedis, y de cada çiento salen çiento y ochenta maravedis, y de diez salen diez y ocho maravedis, y de çinco salen nueve maravedis. $Y$ cada res se rescata de cada millar a dozientos maravedis y no pagan otros derechos. Y tanbien an de registrar el ganado cada año por el dia de San Juan de junio y el derecho se paga por el dicho dia de San Juan de cada vn año segun la dicha costunbre y capitulaçion.

Çenizate: los que biven en el pagan por la dicha costunbre a dos maravedis por 
cada res sean pocas o sean muchas o las que tuvieren y no otro derecho segun la dicha costunbre y capitulaçion.

Los moços asoldados pagan por cabeça segund de la tierra que son y ansi pagan las quatro reses tiniendo de çien cabeças arriba como sy fuese señor de ganado, y si tiene de çien cabeças abaxo como de la tierra de donde fuere syn pagar las dichas quatro reses. 